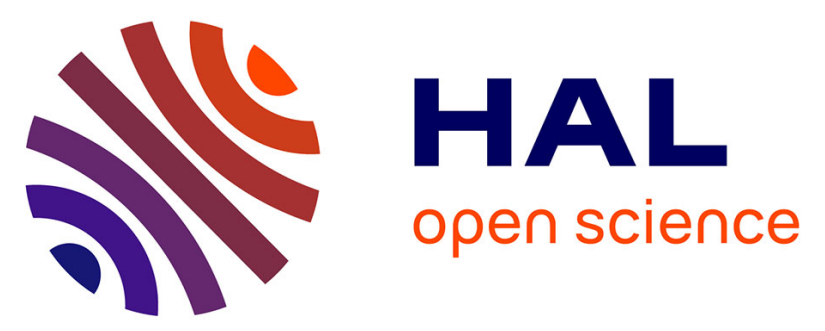

\title{
Characteristics and behaviors in a sample of patients unaware of their infection until AIDS diagnosis in Italy: a cross-sectional study
}

Anna Colucci, Roberta Balzano, Laura Camoni, Vincenza Regine, Benedetta Longo, Patrizio Pezzotti, Fabrizio Starace, Loredana Cafaro, Maria Stella Aloisi, Barbara Suligoi, et al.

\section{To cite this version:}

Anna Colucci, Roberta Balzano, Laura Camoni, Vincenza Regine, Benedetta Longo, et al.. Characteristics and behaviors in a sample of patients unaware of their infection until AIDS diagnosis in Italy: a cross-sectional study. AIDS Care, 2011, pp.1. 10.1080/09540121.2011.554525 . hal-00686085

\section{HAL Id: hal-00686085 https://hal.science/hal-00686085}

Submitted on 7 Apr 2012

HAL is a multi-disciplinary open access archive for the deposit and dissemination of scientific research documents, whether they are published or not. The documents may come from teaching and research institutions in France or abroad, or from public or private research centers.
L'archive ouverte pluridisciplinaire HAL, est destinée au dépôt et à la diffusion de documents scientifiques de niveau recherche, publiés ou non, émanant des établissements d'enseignement et de recherche français ou étrangers, des laboratoires publics ou privés. 

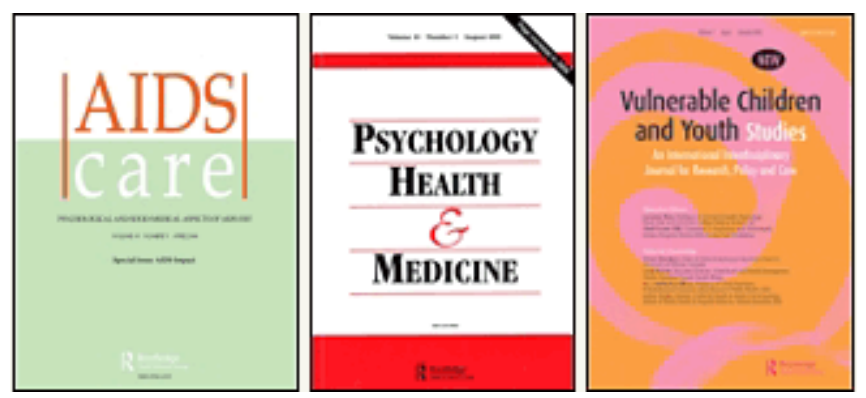

Characteristics and behaviors in a sample of patients unaware of their infection until AIDS diagnosis in Italy: a cross-sectional study

\begin{tabular}{|r|l|}
\hline Journal: & $\begin{array}{l}\text { AIDS Care - Psychology, Health \& Medicine - Vulnerable Children } \\
\text { and Youth Studies }\end{array}$ \\
\hline Manuscript ID: & AC-2010-07-0384.R1 \\
\hline Journal Selection: & AIDS Care \\
\hline Keywords: & AIDS, HIV, late tester \\
\hline \multicolumn{2}{|}{} \\
\hline
\end{tabular}

\section{SCHOLARONE"}

Manuscripts 
Characteristics and behaviors in a sample of patients unaware of their infection until AIDS diagnosis in Italy: a cross-sectional study

Running title: AIDS patients and late testers in Italy

\section{Abstract}

The objective of this study is to define the socio-demographic and behavioral characteristics of people unaware of being HIV-positive at AIDS diagnosis. A multi-center cross-sectional study was conducted in 11 Italian centers of infectious diseases, recruited on a voluntary basis. Each center enrolled individuals diagnosed with AIDS aged $\geq 18$ years from May 2003 to December 2005. The patients were classified into two groups based on the amount of time that elapsed from diagnosis of HIV infection to AIDS diagnosis. "Late testers" were defined as those with a time period of $\leq 6$ months between first HIV positive test and AIDS diagnosis. In order to evaluate the factors independently associated with being a late tester, a multivariate logistic regression model was performed. The McNemar $\chi^{2}$ test was used to analyze behavioral changes before and after HIV diagnosis. During study period 245 patients were enrolled, of these $51.8 \%$ were late testers. The variables independently associated with being a late testers were: being employed; having acquired the infection through sexual contacts; having taken the HIV test because they didn't feel well; having at least one symptom or illness among those indicating infection; not having had paid sex within the 12 months prior to HIV diagnosis. Before and after HIV diagnosis a significant increase in safe sex behaviors was observed among individuals with no delay in diagnosis. However, the proportion of people who continue not using condoms is still high. This study seems to indicate that sexual transmission is often associated to late testing. Individuals enrolled seem to have a low perception of risk, they do not perform HIV testing and consequently miss the opportunity of early diagnosis. 
Keywords: AIDS; HIV; late tester

\section{Introduction}

Since 1996, the large-scale use of combination antiretroviral therapy has contributed considerably to reducing the incidence of AIDS and the correlated mortality of the disease in industrialized countries. In Italy, the number of cases of AIDS reported to The National AIDS has decreased from approximately 5,653 cases registered in 1995 to 1,330 cases in 2008 (COA, 2009).

However, the effectiveness of this therapeutic intervention is limited for a significant proportion of people with AIDS (in Italy in 2008, approximately 60\%) receiving HIV diagnosis in the same time of AIDS diagnosis, therefore without having adequate time for the necessary treatment (COA, 2009). Lack of knowledge of HIV serostatus is harmful to the individual, since it precludes the possibility of benefiting from the interventions that reduce the risk of clinical progression, and constitutes a public health problem because it doesn't allow for taking the necessary actions that can prevent further spread of the infection (Girardi et al., 2000).

Since the late 90s, numerous studies have been conducted in different countries to highlight the socio-demographic and epidemiological characteristics of people who were unaware of being HIV-positive at AIDS diagnosis. Some of these studies were made on a study population of people with AIDS, others focused on individuals at the time of first HIV diagnosis (Castilla et al.,2002; Schwartz et al., 2006; Porter et al., 1993; Couturier et al.,1998; Hocking et al., 2000; Sabin et al., 2004; Delpierre et al., 2007; Adler et al., 2009).

A study conducted in Italy on patients reported to the National AIDS Registry in 1996-2002 have shown that male gender, come from foreign country and have being infected 
trough sexual contacts were associated with an HIV diagnosis close to AIDS diagnosis. (Longo et al., 2005). However, in that study only a limited number of patients characteristics could be analyzed, since data were derived from AIDS surveillance forms.

The present study therefore intent to investigate other characteristics of persons with delayed diagnosis, in particular health status, risk perception and the clinical history.

It is important to identify the characteristics of the "late testers". This will help develop strategies that can give more immediate access to the test for those whose behavior puts them at risk of HIV infection but who are unaware of the risks and therefore do not test (Girardi et al., 2007).

In addition, early diagnosis of HIV in the HAART era guarantees the person who has acquired HIV more efficient management of the disease and the opportunity of defining the optimal time for initiation of antiretroviral therapy. This is where this study can be placed; the objective being to define the socio-demographic and behavioral characteristics of people unaware of being HIV-positive at AIDS diagnosis.

\section{Methods}

A multi-center cross-sectional study was conducted in 11 Italian centers of infectious diseases, recruited on a voluntary basis. Each center enrolled individuals newly diagnosed with AIDS aged $\geq 18$ in the period from May 2003 - to December 2005.

People newly diagnosed with AIDS were divided into groups of "late testers", individuals for whom the time between HIV diagnosis and AIDS diagnosis was $\leq 6$ months, and "non-late testers", individuals with the time between HIV diagnosis and AIDS diagnosis was $>6$ months. This is useful to having a homogeneous sample of people newly diagnosed with AIDS who access to the Centers for Infectious Diseases. 
For all eligible individuals demographic and clinical data were abstracted from hospital records.

An ad hoc questionnaire was administered at the time of the patient's discharge from the hospital by specifically trained personnel to patients who agreed to enter the study and provided written informed consent. The questionnaire included the following sections: sociodemographic information; information regarding the history of the test and infection; information on drug use, sexual behavior and adherence to antiretroviral therapy, for those who were aware of being HIV positive since more than three months.

\section{Outcome definitions}

The patients were classified into two distinct groups based on the amount of time that elapsed from HIV diagnosis to AIDS diagnosis. "Late testers" were defined as those with a time period of $\leq 6$ months between HIV diagnosis and AIDS diagnosis. Then, the association of specific information contained in the questionnaire and the two groups of patients with AIDS (late testers and non-late testers) was assessed. In order to evaluate the factors independently associated with being a late tester, a multivariate logistic regression model was performed, including variables associated with late testing with a p-value of $<0.10$ in univariate analysis, as well as age and gender.

The McNemar $\chi^{2}$ test was utilized to analyze separately for the late and non-late testers behavioral changes (sexual and drug use) before and after HIV diagnosis. Data analysis was made with SPSS 17.0.

\section{Results}

From May 2003 to December 2005, 472 patients were considered for the inclusion in the study, and 245 of these $(51.8 \%)$ were actually enrolled and completed the questionnaire. 
The 227 individuals who did not participate differed from the 245 participating individuals for: main modality of acquiring the infection (among participants: "heterosexual" 45.3\%; among non-participants: injecting drug users - IDUs 37.9\%); level of CD4+ at AIDS diagnosis (CD4+ $\leq 200$ cells/ $\mu 1: 89.7 \%$ among participants and $83.3 \%$ among nonparticipants) and proportion of late testers (51.8\% among participants and 38.8\% among non-participants). There were no significant differences between the two groups regarding gender, age, marital status or nationality.

Among the 245 participating individuals, 127 (51.8\%) were late testers (Table 1). Table 1 shows the social-demographical characteristics of the late testers compared to the non-late testers and shows the crude (cOR) and adjusted odds ratio (aOR) associated with being a late or non-late tester.

In multivariate analysis, the variables independently associated with being a late testers were: being employed; having acquired the infection through sexual contacts (homobisexual and heterosexual); having taken the HIV test because they didn't feel well; having at least one symptom or disease among those indicating infection; not having had paid sex within the 12 months before to HIV diagnosis.

The same variables are significantly associated with being a late tester, both for individuals who acquired the infection through sexual contact and those who acquired it through injecting drug use (data not shown).

Among the late testers, there was a significantly higher percentage $(15.7 \%)$ of individuals with two or more AIDS defining diseases compared to the non-late testers $(5.1 \%)$. The most frequent disease, in both later testers and non-late testers was Pneumocystis jiroveci pneumonia (22.8\% and $20.3 \%$, respectively). In the late testers vs. non-late testers, there was a greater proportion of diagnosis of Cerebral toxoplasmosis (11.8\% vs. 5.9\%), Cytomegalovirus disease (11.8\% vs. $4.2 \%)$ and Kaposi's sarcoma (9.4\% vs. $1.7 \%)$ and a 
lower proportion of diagnosis of Burkitt's lymphoma (4.7\% vs.11.9\%) and AIDS Dementia complex (3.1\% vs. $10.2 \%)$ (Table 2$)$.

Table 3 shows the behavioral analysis (sexual and drug use) before and after HIV diagnosis. Both the late testers and non-late testers had fewer sexual relations with their regular partners after HIV diagnosis. Among the non-late testers who continued having sex with their regular partners, the percentage of those always using safe sex measures increased significantly. The percentage of those who had sex with occasional partners before and after HIV diagnosis was significantly reduced in the late testers. No reduction of the number of contacts with occasional partners was observed in those individuals with no delay in diagnosis, but there was a significant increase in safe sex behaviors. In both groups, after six months of HIV diagnosis, there was a significant decrease in drug use and in injected drug use specifically.

\section{Discussion}

In our sample, more than half of the individuals studied were unaware of having HIV infection before AIDS diagnosis. This is a higher proportion than what can be found in an Italian study (Longo et al., 2005), but still corresponds to the national average registered by COA/ISS (COA, 2009). This diversity can also be explained by the characteristics of the sample being studied which consists entirely of people newly diagnosed with AIDS, defined as late testers, with a time interval of $\leq 6$ months between HIV and AIDS diagnosis. In fact, other studies took into account the time interval between the first positive test and AIDS diagnosis which was extremely variable, ranging from 1 to 12 months (Girardi et al., 2000; Castilla et al., 2002; Schwartz et al., 2006; Porter et al., 1993; Couturier et al., 1998; Hocking et al., 2000; Chadborn et al., 2006; Wortley et al., 1995; Brännström et al., 2005). Other studies refer to the CD4 cell count where CD4 $\leq 200$ cells/ $\mu$ (Chadborn et al., 2006). 
Therefore, it is important to consider which population is being studied: people newly diagnosed with HIV, people recently infected with HIV, people newly diagnosed with AIDS in order to compare data from different countries (Adler et al., 2009). Our study population consists of people newly diagnosed with AIDS.

The results of the present study are consistent with those of a previous analysis conducted in an Italian AIDS study (Longo et al., 2005) and provide additional information on other risk factors for late diagnosis including being employed, having being tested because of feeling ill, not reporting paid sexual intercourses.

Unlike other studies (Delpierre et al., 2008), our study shows that being employed is associated with being a late tester. Analyzing the characteristics of this person, the information that emerges is that employed people compared to non-employed people are more frequently male, with a high level of education who have acquired the infection through heterosexual sexual contacts and tested for HIV because they had symptoms such as fever of long duration, weight loss, and before knowing that they were HIV+ had more frequently been diagnosed with syphilis and gonorrhea.

Probably the socio-economic status of the employed person did not lead their doctor to suggest taking the HIV test despite the presence of symptoms and sexually transmitted diseases. In fact, less than one-third of the workers took the test on the advice of their specialist doctor.

As also reported in other studies (Schwartz et al., 2006; Porter et al., 1993; Couturier et al.,1998; Hocking et al., 2000; Longo et al. 2005), this study seems to indicate that sexual transmission is often associated to late testing while injecting drug use is more common among the non-late testers. It is possible that, a number of information campaign focused on sexual transmission have been conducted in Italy (Frati et al., 2002), there is still a low perception of the risk of acquiring infection trough sexual contacts. In addition, IDUs are 
more easily identifiable by health care workers due to the fact that these people access drug addiction services and are therefore strongly urged to take the test whereas it is not as easy for people who engage in risky sexual behavior who could have fewer opportunities to access services of prevention, diagnosis and treatment of HIV infection (CDC, 2003; Castelnuovo et al., 2003).

Even the different distribution of the AIDS defining pathologies in the individuals participating in the study seems to indicate that sexual relations are the main means of transmitting the virus among late testers. In fact, it is known that Kaposi's sarcoma is the most common pathology among AIDS patients who contracted the virus through sexual contact (Dal Maso et al., 2009).

The high proportion of late testers who had contracted HIV through sexual contacts (heterosexual and homo/bisexual) raises great concern since these two modes account for almost $70 \%$ of the new cases of AIDS registered by the National AIDS Registry in 2008 (COA, 2009). Moreover, not having had paid sexual relations within the 12 months prior to HIV diagnosis is associated to being a late tester. Some studies show that among heterosexuals, late testers are more frequently people with a stable relationship and less frequently people with a higher number of sexual partners (Castelnuovo et al., 2003, Borghi et al., 2008). Probably, people who did not have occasional sexual contacts or paid sexual contacts had a lower risk perception. In addition, it would seem that healthcare providers do not consider them a priority target for offering the test (Girardi et al., 2007).

Taking the test because one did not feel well and having at least one symptom or illness among those suggesting infection are variables associated with being a late tester. Individuals seem to have a low risk perception, they do not perform HIV testing and consequently miss the opportunity of early diagnosis (Girardi et al., 2000; Brännström et al., 2005; Girardi et al., 2004). 
Lastly, behavioral analysis made before and after HIV diagnosis has allowed for identifying late testers as tending to reduce sexual relations with steady or occasional partners while non-late testers only reduce sex with occasional partners but increase condom use in all sexual practices. However, the proportion of people who continue not using condoms is still high (Sudarshi et al., 2008; Camoni et al., 2009). It must be stressed that the importance of this result is limited by the low number of answers provided by the late testers in this part of the questionnaire.

Some limitations of this study need to be mentioned. In the first place, the significance of the sample is limited to the enrolment procedure which was not uniform among the centers throughout the entire period of the study. In addition, the enrolled patients are only half of those initially included in the study. On the other hand, we must consider that the demographic and epidemiological characteristics of the sample that was studied are similar to the characteristics of the AIDS cases that were reported in Italy during the same period and were also the subject of study which was examined from 1996 to 2002 (COA, 2009; Castelnuovo et al., 2003). This study might underestimate the percentage of late testers. It was observed that there was a higher proportion of late testers among those patients who refused the interview. The proportion of late testers among enrolled subjects, including those who accepted to participate as well as those who refused to participate is $55 \%$. This could constitute a strong bias that might have affected the relevance of the results.

The study shares the limitations of surveys by questionnaires, especially in the sections investigating sexual behavior and drug abuse. Moreover, the complexity of the questionnaire required a structured interview.

Even taking these limitations in consideration, the study provides useful information and highlights the need to identify a strategy for easier access to the test, especially for the heterosexual population. Finally, the results seem to suggest that it would be opportune to 
raise awareness among healthcare providers to put more attention to clinical symptoms and promote greater awareness regarding the need for HIV testing, not only as a response to high risk behaviors for acquiring HIV infection. 


\section{Acknowledgments}

Giovanni Di Perri, Cristina Cometto (Clinica Malattie Università di Torino); Antonella D’Arminio Manforte, Federica Tordato (Clinica Malattie Infettive, Università di Milano); Claudio Arici, Laura Ravasio (Malattie Infettive Ospedali Riuniti, Bergamo); Giampiero Carosi, Giuseppe Paraninfo, Silvia Campostella e Cristina Zeni (Clinica Malattie Infettive, Università di Brescia); Vanni Borghi (Clinica Malattie Infettive Università di Modena); Alessandro Sanpaolesi, Lucia Alba (INMI L.Spallanzani, Roma); Josè Fiore, Maria Grazia Tateo (Clinica Malattie Infettive, Università di Bari); Maria Stella Mura, Marco Cilliano (Clinica Malattie Infettive, Università di Sassari); Laura Sighinolfi (Ospedale S. Anna, Ferrara); Vincenzo Colangeli, Teresa Sebastiani (Ospedale S. Orsola, Bologna); Francesco Mazzotta, Massimo Di Pietro (Ospedale S. Maria Annunziata, Firenze) 


\section{References}

Adler A., Mounier-Jack S. \& Coker R.J. (2009). Late diagnosis of HIV in Europe: definitional and public health challenges. AIDS Care 21(3), 284-293.

Borghi V., Girardi E., Bellelli S., Angeletti C., Mussini C., Porter K. et al. (2008). Late presenters in an HIV Surveillance System in Italy during the period 1992-2006. Journal of Acquired Immune Deficiency Syndrome, 49(3), 282-286.

Brännström J., Akerlund B., Arneborn M., Blaxhult A., Giesecke L. (2005). Patients unaware of their HIV infection until AIDS diagnosis in Sweden 1996-2002 - a remaining problem in the highly active antiretroviral therapy era. International Journal of STD \& AIDS International, 16(10), 702-706.

Camoni L., Regine V., Colucci A., Dal Conte I., Chiriotto M., Vullo V., et al. (2009). Changes in at-risk behaviour for HIV infection among HIV-positive persons in Italy. AIDS patient care and STDs, 23(10), 853-858.

Castelnuovo B., Chiesa E., Rusconi S., Adorni F., Bongiovanni M., Melzi S., et al. (2003). Declining incidence of AIDS and increasing prevalence of AIDS presenters among AIDS patients in Italy. European Journal of Clinical Microbiology \& Infectious diseases, 22(11), 663-669.

Castilla J., Sobrino P., De La Fuente L., Noguer L., Guerra L., \& Parras F. (2002). Late diagnosis of HIV infection in the era of highly active antiretroviral therapy: consequences for AIDS incidence. AIDS, 16, 1945-1951. 
Centers for Disease Control and Prevention (2003). Late versus early testing of HIV--16 Sites, United States, 2000-2003. MMWR Morbidity and Mortality Weekly Report, $52(25), 581-586$.

Centro Operativo AIDS - COA. (2009). Aggiornamento delle nuove diagnosi di infezione da HIV e dei casi di AIDS notificati in Italia al 31 dicembre 2008. Notiziario dell'Istituto Superiore di Sanità, 22(3) Suppl.1. Retrieved from: http://www.iss.it/binary/publ/cont/onlinecoa1.pdf.

Chadborn T.R., Delpech V.C., Sabin C.A., Sinka K. \& Evans B.G. (2006). The late diagnosis and consequent short-term mortality of HIV-infected heterosexuals (England and Wales, 2000-2004). AIDS, 20(18), 2371-2379.

Couturier E., Schwoebel V., Michon C., Hubert J.B., Delmas M.C., Morlat P. et al. (1998). Determinants of delayed diagnosis of HIV in France 1993-1995. AIDS, 2(7), 795-800.

Dal Maso L., Polesel J., Serraino D., Lise M., Piselli P., Falcini F., et al. (2009). Pattern of cancer risk in persons with AIDS in Italy in the HAART era. British Journal of Cancer, $100,840-847$.

Delpierre C., Cuzin L., Lauwers-Cances V., Datta G.D, Berkman L., \& Lang T. (2008). Unemployment as a risk factor for AIDS and death for HIV-infected patients in the era of highly active antiretroviral therapy. Sexually Transmitted Infections, 84(3), 183-186.

Delpierre C., Dray-Spira R., Cuzin L., Marchou B., Massip P., Lang T., et al. (2007). Correlates of late HIV diagnosis: implications for testing policy. International Journal of STD \& AIDS International, 18(5), 312-317. 
Frati A., Cordone M. N. (2002). The Italian Ministry of Health's AIDS information educational campaigns between 1988-2002. Bollettino per le Farmacodipendenze e l'Alcoolismo, $\quad$ XXV (1-2), 11-18. Retrieved from: http://www.unicri.it/min.san.bollettino/bulletin_it/bull2002.htm

Girardi E., Aloisi M.S., Arici C., Pezzotti P., Serraino D., Balzano R., et al. (2004). Delayed presentation and late testing for HIV: demographic and behavioral risk factors in a multicenter study in Italy. Journal of Acquired Immune Deficiency Syndrome, 36(4), 951-959.

Girardi E., Sabin C.A., \& d'Arminio Monforte A. (2007). Late diagnosis of HIV infection: epidemiological features, consequences and strategies to encourage earlier testing. Journal of Acquired Immune Deficiency Syndrome, 46 Suppl 1:S3-8.

Girardi, E., Sampaolesi A., Gentile M., Nurra G., \& Ippolito G. (2000) lncreasing proportion of late diagnosis of HIV infection among patients with AIDS in Italy following introduction of combination antiretroviral therapy. Journal of Acquired Immune Deficiency Syndrome, 25(1), 71-76.

Hocking J.S., Rodger A.J., Rhodes D.G., \& Crofts N. (2000). Late presentation of HIV infection associated with prolonged survival following AIDS diagnosis - characteristics of individuals. International Journal of STD \& AIDS, 11(8), 503-508.

Longo B., Pezzotti P., Boros S., Urciuoli R. \& Rezza G.(2005). Increasing proportion of late testers among AIDS cases in Italy, 1996-2002. AIDS Care, 17(7), 834-841.

Porter K., Wall P.G., \& Evans B.G. (1993). Factor associated with lack of awareness of HIV infection before diagnosis of AIDS. British Medical Journal, 307, 20-23. 
Sabin C., Smith J., Gumly H., Murphy G., Lampe F.C., Phillips A.N. (2004). Late presenters in the era of highly active antiretroviral therapy: uptake of and responses to antiretroviral therapy. AIDS, 18, 2145-2151.

Schwartz S., Hsu L., Dilley J W., Loeb L., Nelson K., \& Boyd S. (2006). Late diagnosis of HIV infection. Trends, prevalence, and characteristics of persons whose HIV diagnosis occurred within 12 months of developing AIDS. Journal of Acquired Immune Deficiency Syndrome, 45(4), 491-494.

Sudarshi D., Pao D., Murphy G., Parry J., Dean G., \& Fisher M. (2008). Missed opportunities for diagnosing primary HIV infection. Sexually Transmitted Infections, 84(1), 14-16.

Wortley P.M. et al. (1995). HIV testing: patterns: where, why and when were persons with AIDS tested for HIV. AIDS, 20, 2371-2379. 
Table 1 - Factors associated with being a late tester (crude and adjusted odds ratios).

$\begin{array}{llllllll} & \text { total } & \text { late tester } & \% & \text { cOR } & 95 \% \text { CI } & \text { aOR } & \text { 95\% CI } \\ \text { Total } & 245 & 127 & 51.8 & & \end{array}$

Gender

Male

Female

Age (mean $\pm d s)$

Age

$<35$

$35-44$

$\geq 45$

\section{Area of origin}

Outside Italy

Italy

$\begin{array}{ll}40 & 26 \\ 205 & 101\end{array}$

65.0

$1.91 *$

0.94-3.87

49.3

1

$\begin{array}{ll}3.00 * * & 1.42-6.35 \\ 1.00 & \\ 1.96 * * & 1.10-3.49\end{array}$

$1.99 \mathrm{~ns}$

1.00

$1.88 \mathrm{~ns}$

$0.80-4.42$

\section{Education}

$<8$ years

$136 \quad 60$

44.1

1.00

1.00

$105 \quad 66$

62.9

$2.14 * *$

1.27-3.61

$1.24 \mathrm{~ns}$

$0.55-2.76$

\section{Being employed}

No

$89 \quad 23$

$154 \quad 104$

25.8

1.00

67.5

$5.97 * * *$

$3.33-10.68$

1.00

$4.60 * * *$

1.98-10.66

Mode of acquisition the

infection

IDUs

Homo/bisexual contacts

80

11

13.8

1.0

1.00

Heterosexual contacts

72.7

$16.7 * * *$

7.25-38.56

$9.22 * * *$

$3.19-26.63$

Not reported

$82 \quad 57$

69.5

$14.3^{* * *}$

6.48-31.54

$14.41 * * *$

4.85-42.85

64.7

$11.5^{* * *}$

3.53-37.45

$9.01 * *$

$1.91-42.38$

Place where the first

HIV+ test was

performed

Public outpatient clinic

During hospitalization

$122 \quad 65$

53.3

1.00

1.00

Drug addiction

$74 \quad 49$

66.2

$1.72 *$

$0.94-3.13$

$1.49 \mathrm{~ns}$

$0.60-3.71$

$0.16 \mathrm{~ns}$

0.02-1.48

$27 \quad 1$

3.7

$0.03 * * * \quad 0.00-0.26$ 
Private outpatient clinic 16

56.3

$1.13 \mathrm{~ns}$

$0.39-3.22$

$1.20 \mathrm{~ns}$

$0.29-4.89$

\section{Reasons for HIV testing}

Feeling bad $108 \quad 76$

70.4

$7.52 * * *$

$3.48-16.23$

$4.98 * *$

$1.75-14.17$

At risk behavior

24.0

1.00

1.00

Prescribed by doctor

$82 \quad 36$

43.9

$2.48 * * *$

$1.13-5.42$

$2.63 *$

$0.89-7.80$

\section{Who suggested HIV test}

Specialist doctor

60.6

$3.21 * * *$

1.79-5.73

$0.96 \mathrm{~ns}$

$0.34-2.68$

Other (partner, friend,

self-prescribed)

$74 \quad 24$

32.4

1.00

1.00

At least one symptom or illness

No

$57 \quad 20$

35.1

1.00

1.00

Yes

$188 \quad 107$

56.9

$2.44 * * *$

$1.32-4.52$

$4.13 * *$

$1.63-10.46$

Hospitalization

12

months before the first

HIV+ test

No

$183 \quad 91$

49.7

1.00

1.00

Yes

$49 \quad 31$

63.3

$1.74 *$

$0.91-3.33$

$1.17 \mathrm{~ns}$

$0.43-3.18$

Occasional partners 12

months before HIV

diagnosis

No

No
Yes

$107 \quad 65$

60.7

$1.94 * *$

$1.16-3.26$

$1.97 \mathrm{~ns}$

$0.82-4.67$

$133 \quad 59$

44.4

1.00

1.00

\section{Paid sexual intercourses}

12 months before HIV

\section{diagnosis}

No

$176 \quad 102$

58.0

$2.69 * * *$

$1.47-4.93$

$6.45 * *$

1.62-10.29

Yes

$62 \quad 21$

33.9

1.00

1.00

In this table were reported variables associated with being a late tester in univariate analysis with $\mathrm{p}$-value $<0.10$.

ns not significant ( $\mathrm{p}$-value $>0.10)$

* p-value $<0.10$

$* *$ p-value $<0.05$

$* * *$ p-value $<0.001$ 
Table 2 - Clinical characteristics at AIDS diagnosis: CD4 cell count and most frequent AIDS-defining illnesses

\begin{tabular}{|c|c|c|c|c|c|c|}
\hline & \multicolumn{2}{|c|}{ Total $(\mathrm{N}=\mathbf{2 4 5})$} & \multicolumn{2}{|c|}{ Non- late testers $(\mathrm{N}=118)$} & \multicolumn{2}{|c|}{ Late testers $(\mathrm{N}=127)$} \\
\hline & $\mathbf{N}$ & $\%$ & $\mathbf{N}$ & $\%$ & $\mathbf{N}$ & $\%$ \\
\hline $\begin{array}{l}\text { Median CD4 cell count } \\
\text { (IQR) }\end{array}$ & $61(22-174)$ & & $103(35-190)$ & & $41(18-99)$ & \\
\hline $\begin{array}{l}\text { Pneumocystis jirovecii } \\
\text { Pneumonia }\end{array}$ & 53 & 21.6 & 24 & 20.3 & 29 & 22.8 \\
\hline Oesophageal candidiasis & 29 & 11.8 & 14 & 11.9 & 15 & 11.8 \\
\hline Pulmonary Tuberculosis & 23 & 9.4 & 13 & 11.0 & 10 & 7.9 \\
\hline Toxoplasmosis & 22 & 9.0 & 7 & 5.9 & 15 & 11.8 \\
\hline Wasting syndrome & 22 & 9.0 & 11 & 9.3 & 11 & 8.7 \\
\hline Burkitt's lymphoma & 20 & 8.2 & 14 & 11.9 & 6 & 4.7 \\
\hline Cytomegalovirus & 20 & 8.2 & 5 & 4.2 & 15 & 11.8 \\
\hline AIDS-dementia complex & 16 & 6.5 & 12 & 10.2 & 4 & 3.1 \\
\hline Kaposi's sarcoma & 14 & 5.7 & 2 & 1.7 & 12 & 9.4 \\
\hline Multiple concomitant AIDS- & 26 & 10.6 & 6 & 5.1 & 20 & 15.7 \\
\hline
\end{tabular}

defining illnesses 
Table 3 - Sexual behavior and drug use before and after diagnosis of HIV infection

$$
\text { Non- late testers }
$$

\section{Before}

HIV

diagnosis \%

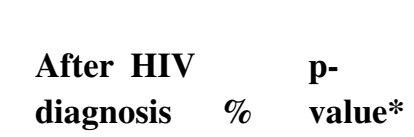

Sexual contacts

with stable

partners

No

Yes

Total

Condom use in sexual contacts with stable partners§

-Vaginal sex

Never/sometimes $\quad 34$

Always

5

Total

39

-Anal sex

Never/sometimes 22

Always

3

Total

25

-Performing oral

sex

Never/sometimes 32

Always

2

Total 34

-Receiving oral sex

Never/sometimes $\quad 30$

Always

2

Total

Sexual contacts
with

partners

No

$\begin{array}{ll}87.2 & 20 \\ 12.8 & 19 \\ & 39\end{array}$

51.3

48.7

39

$\begin{array}{ll}88.0 & 16 \\ 12.0 & 9 \\ & 25\end{array}$

0.031

$\begin{array}{ll}64.0 & 1 \\ 36.0 & 2 \\ & 3\end{array}$

33.31

66.72

33.3

66.7

3

3

55.6

44.4
0.375

1.000

1.000

$\begin{array}{ll}94.1 & 26 \\ 5.9 & 8\end{array}$

76.5

23.5

0.031

50.0

50.0

$25.0 \quad 2$

4

0.063

1.000

$\begin{array}{ll}93.8 & 25 \\ 6.3 & 7 \\ & 32\end{array}$

78.1

21.9

3

$75.0 \quad 2$

50.0

$25.0 \quad 2$

50.0 p-

value* 0.000

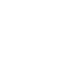

$\begin{array}{lll}25.9 & 42 & 77.8 \\ 74.1 & 12 & 22.2 \\ & 54 & \end{array}$




$\begin{array}{llllllll}\text { Yes } & 73 & 64.6 & 69 & 61.1 & 33 & 58.9 & 7 \\ \text { Total } & 113 & & 113 & & 56 & & 56\end{array}$

Condom use in sexual contacts with occasional partners**

-Vaginal sex

Never/sometimes

Always

35

10

Total

45

-Anal sex

Never/sometimes

Always

Total

40

-Performing oral

sex

Never/sometimes $\quad 37$

Always

2

Total

39

-Receiving oral sex

Never/sometimes

Always

Total

41

$95.1 \quad 30$

$4.9 \quad 11$

41

Drug use $\mathrm{e}^{* * *}$

No

Yes

31

82

$27.4 \quad 70$

$72.6 \quad 43$

Total

113
$77.8 \quad 22$

$22.2 \quad 23$

45

$77.5 \quad 20$

$22.5 \quad 20$

40

0.000

$48.9 \quad 3$

51.1

0

3

0.003

50.0

50.0

$94.9 \quad 27$

$5.1 \quad 12$

39

30.8

0.002

100.03

$0.0 \quad 0$

3

56

$50.0 \quad 2$

$50.0 \quad 2$

4

4

$\begin{array}{ll}75.0 & 3 \\ 25.0 & 1 \\ & 4\end{array}$

4 nc

100.0

0.0

1.000

50.0

50.0

1.000

75.0

25.0

0.004

1.000

$\begin{array}{lll}75.0 & 3 & 75.0 \\ 25.0 & 1 & 25.0 \\ & 4\end{array}$

0.000

$\begin{array}{lllll}61.9 & 80 & 70.8 & 99 & 87.6\end{array}$

$\begin{array}{lllll}38.1 & 33 & 29.2 & 14 & 12.4\end{array}$

113113

Injecting drug

use $* * *$

0.000

0.031

No

42

$40.4 \quad 85$

81.7

87

91.693

97.9

Yes

62

59.619

18.3

8

8.42

2.1

Total

104

104

95

95

\footnotetext{
* Mc Nemar test for paired data

** 12 months before and after HIV diagnosis

*** 6 months before and after HIV diagnosis
} 